\title{
INFLUENCE OF SCORING MODE AND AGE GROUP ON PASSING ACTIONS DURING SMALL-SIDED AND CONDITIONED SOCCER GAMES
}

original paper

doi: https://doi.org/10.5114/hm.2017.73621

\author{
CARLOS H. ALMEIDA ${ }^{1}$, ANNA VOLOSSOVITCH ${ }^{2}$, RICARDO DUARTE ${ }^{2,3}$ \\ ${ }^{1}$ CIDEF, Instituto Superior Manuel Teixeira Gomes, Portimão, Portugal \\ ${ }^{2}$ CIPER, Faculdade de Motricidade Humana, SpertLab, Universidade de Lisboa, Lisbon, Portugal \\ ${ }^{3}$ Vaasan Palloseura Football Club, Vaasa, Finland
}

\begin{abstract}
Purpose. The study examined the influence of scoring mode (line goal, double goal, and central goal) and age group (U13 and U15) on passing actions performed by youth soccer players during 4v4 small-sided and conditioned games (SSCG).

Methods. In 6 independent sessions, participants performed the 3 SSCGs, each lasting $10 \mathrm{~min}$, in a total of $60 \mathrm{~min}$ per game condition. Overall, 4052 passes were notated post-event with the Lince software. The analysis included 3 game-related dependent variables: passing volume, passing zones, and passing direction. Mixed factorial ANOVA and multinomial logistic regression were applied to evaluate the effects of scoring mode and age group on dependent variables.

Results. A greater passing volume was found in line goal (vs. central goal), while the U15 group performed significantly more passing actions than the U13 group. Logistic regression models revealed the following significant main effects of scoring mode and age: (1) double goal (vs. central goal) increased the odds of performing passing actions in defensive lateral zones; (2) line goal (vs. central goal) increased the passing flow in defensive midfield and offensive midfield sectors and decreased the odds of executing forward passes; (3) U13 teams were more likely than U15 to execute passing actions in more advanced pitch zones and less likely to pass sideways.

Conclusions. The manipulation of scoring mode in SSCGs influenced the quantity, location, and dominant direction of passing actions to achieve specific task solutions. The findings provide soccer coaches with relevant information for the selection of representative tasks and optimization of task design in youth soccer practice.
\end{abstract}

Key words: youth soccer, performance analysis, task constraints, expertise, skill acquisition

\section{INTRODUCTION}

Small-sided and conditioned games (SSCGs) represent a type of playing form activity widely used in youth soccer training programs $[1,2]$. These activities are considered very important for the development of expertise in team sports, especially when proposed to players of younger age groups $[1,3,4]$. This assertion relies on the principle that younger and novice players can be more susceptible to learn and improve fundamental skills to perform successfully in competitive tasks [3-5]. The inherent instability provided by systematic manipulation of task constraints during SSCGs is useful for learners to actively explore the balance between stable and variable movement solu- tions in achieving specific task goals [4-6]. Therefore, one important challenge for youth soccer coaches is to carefully manipulate task constraints in order to guide learners toward functional and adaptive behaviours during game-play scenarios [6-8].

In the last few years, the manipulation of scoring mode in SSCGs (i.e. size, number, shape, and/or positioning of goals) has been in the sphere of interest of sports sciences research. Empirical evidence has suggested that different scoring modes influence physi$\mathrm{cal} /$ physiological responses [9-11], technical actions $[8,10-12]$, and tactical behaviours $[8,13,14]$ of soccer players during several SSCGs. For instance, the line goal constraint (i.e. crossing the opposing end line with the ball under control) induced more randomness in

Correspondence address: Carlos Humberto Almeida, CIDEF, Instituto Superior Manuel Teixeira Gomes, Rua Dr. Estêvão de Vasconcelos, n. 33 A, 8500-656 Portimão, Portugal, e-mail: carlosalmeida83@hotmail.com

Received: November 30, 2017

Accepted for publication: January 2, 2018

Citation: Almeida CH, Volossovitch A, Duarte R. Influence of scoring mode and age group on passing actions during small-sided and conditioned soccer games. Hum Mov. 2017;18(5)special/issue:125-134; doi: https://doi.org/10.5114/hm.2017.73621. 
C.H. Almeida, A. Volossovitch, R. Duarte, Passing actions in small-sided and conditioned games

the heart rate responses of youth players (U13 and U15) compared with double goal (i.e. 2 small goals placed widely at each goal line) and central goal (i.e. a small goal placed at the middle of each goal line) conditions in 4v4 SSCGs [9]. Further comparisons have shown that central goal condition increased the heart rate responses in adult amateur players in different SSCG formats (2v2, 3v3, and 4v4) [10], and also augmented the physiological load and volume of play of U17 soccer players in 4v4 games [11]. Furthermore, the line goal condition increased the distance covered, the movement speed, and the number of attacks with the ball among adult amateur players in $2 \mathrm{v} 2,3 \mathrm{v} 3$, and $4 \mathrm{v} 4$ situations [10]. It has also been found that U13 and U15 teams, when playing 4v4 SSCGs under this constraint, had higher probabilities to regain possession through tackle and in the defensive midfield sector, decreasing the odds of successful interceptions [8]. The double goal constraint promoted a higher frequency of received balls [10] and turns [12], and decreased the odds of regaining possession through turnover and with elongated playing shapes $[8,14]$ in various SSCG formats. Another study revealed that adding small goals in 5v5 games facilitated the spatial positioning and covered area of professional players by encouraging teams to play far away from each other and with lower space covered [13].

The scoring mode manipulation in SSCGs has multiple implications on the sport-specific performance of individuals and teams. Previous research has shown that older [8, 15-17] and higher skilled players [18] tend to preferably adopt flattened playing shapes during SSCGs, which reflect a more evolved tactical expertise as compared with deeper spatial distributions of younger and less skilled counterparts, who played more individually [16-18]. Besides, the technical actions executed in representative training tasks are also influenced by the players' experience and level of expertise. Almeida et al. [19] reported that experienced U15 players performed longer offensive sequences, with greater figures of players involved, ball touches, and passing actions, than non-experienced practitioners in $\mathrm{Gk}+3 \mathrm{v} 3+\mathrm{Gk}$ and $\mathrm{Gk}+6 \mathrm{v} 6+\mathrm{Gk}$ game situations. Despite the growing amount of empirical evidence on how scoring mode influences individual and collective performances in SSCGs, understanding how players with different attributes (e.g., age, skill, and/ or experience) behave in various practice task conditions is also paramount for coaches to optimize the learning process design in youth soccer $[8,15,19]$. In this respect, to the best of our knowledge, no study has objectively attempted to examine the influence of scoring mode manipulations on the emergence of passing actions performed by players of different age groups.

Passing is a key skill underlying successful performance in soccer $[4,12,20]$. Recently, a couple of studies highlighted the importance of investigating beyond the traditional passing frequencies to analyse performance in game-play environments [21, 22]. The simple association between total passing frequencies and performance effectiveness provides coaches with little information to design representative tasks and guide training drills. The present work intends to overcome this limitation by proposing 3 complementary variables (i.e. passing volume, passing zones, and passing direction) to characterize passing actions that support attacking play in different on-field practice tasks. In particular, changing the number, dimensions, and/ or shape of scoring targets may affect the pitch zones explored by youth players to pass the ball to a teammate $[6,13]$. However, the real consequences of these task variations on passing remain unclear. In this paper, we extend upon our earlier work on the defensive performance [8] by examining the effects of manipulating the scoring mode on passing actions performed by U13 and U15 players during 4v4 SSCGs. We hypothesized that: (1) disregarding the age group, the manipulation of scoring mode influences the passing actions of youth players; (2) older and younger players perform different passing behaviours, irrespective of scoring mode constraints.

\section{MATERIAL AND METHODS}

\section{Participants}

The participants were 16 male soccer players from 2 age groups (U13, $n=8$, mean age: $12.61 \pm 0.65$ years, training experience: $4.63 \pm 0.52$ years; U15, $n=8$, mean age: $14.86 \pm 0.47$ years, training experience: $6.13 \pm 1.55$ years) indicated by their head coaches, considering two main criteria: (i) usual playing position, with a similar proportion of defenders, midfielders, and forwards; (ii) playing level (i.e. similar technical, tactical, and fitness skills). All players were part of the same sports club and both age groups were competing at the regional playing level, performing three 90-min practice sessions and one official match per week. The selected outfield players of each age group were assigned by their respective head coach to 2 balanced teams, in accordance with the coaches' subjective criteria. Teams remained unchanged throughout the protocol. Within each age group, teams competed against each other in all SSCG formats. Parental 
informed written consent was received prior to the experiment, which followed the guidelines stated by the local university Research Ethics Committee and the recommendations of the Declaration of Helsinki.

\section{Procedures}

The study was conducted over a 3-week period at the end of the season, with both age groups completing a protocol consisting of 6 independent sessions. In each session, the participants performed 3 SSCGs during 10-min periods interspersed with $5 \mathrm{~min}$ of passive recovery, yielding a total of 18 games per each age group. The 4v4 SSCG without goalkeepers was the basis of the experimental task. The central goal scoring mode was adopted as the control condition owing to its similarity to games commonly played on a reduced pitch size with a lower number of players [8]. The scoring mode was manipulated in two conditions: (1) line goal, scoring by controlling the ball in the opposing end line; (2) double goal, scoring in either of 2 lateral small goals $[8,9]$. The order effect was neutralized by ensuring a balanced and predetermined distribution of SSCGs for the whole experiment (i.e. sessions 1 and 4: line goal-double goal-central goal; sessions 2 and 5: central goal-line goal-double goal; sessions 3 and 6: double goal-central goal-line goal).

Both age groups performed on the same pitch surface (artificial turf) and under similar weather to standardize experimental conditions [23]. All SSCGs were played on a pitch measuring $30 \times 20 \mathrm{~m}$ (length $\times$ width) with an individual playing area of $75 \mathrm{~m}^{2}[8,9]$. The participants performed a 10-min warm-up routine in each session, including joint mobility exercises, control/passing drills, and dynamic stretching. A week before the experimental protocol, a pilot session was conducted to promote the familiarization of all players with task constraints. This session lasted for 2 hours and the players from both age groups performed each game condition at their best level during $10 \mathrm{~min}$, with 5 min of passive recovery. No instructions or feedbacks about game-play were conceded throughout the protocol. All usual official soccer rules were implemented apart from the offside rule. The same neutral assistant refereed all the SSCGs.

Disc markers were used to signalize sectors and corridors on the pitch. The scoring mode was defined by training cones and hurdles: line goal $(1 \times 20 \mathrm{~m}$; length $\times$ width), double goal $(1 \times 1.5 \mathrm{~m}$; height $\times$ width $)$, and central goal $(1 \times 3 \mathrm{~m})$ (Figure 1$)$. Four assistants with balls (size 5) were placed around the pitch to ensure minimal stoppages during game-play [8].

Data collection

The SSCGs were recorded with a digital video camera (Sony DCR-SR77, Sony ${ }^{\circledR}$ Corporation, China) positioned $20 \mathrm{~m}$ from the closest touchline of the pitch, at the level of the halfway line and with an elevation of $12 \mathrm{~m}$. In each SSCG, passing actions were notated postevent for both teams with the Lince software program (version 1.2.1) [24]. Here, we defined a pass as an intentional and successful technical action of kicking/heading the ball to a teammate during the attack $[20,25]$. The total of 4052 passing actions were identified and analysed. Independent and dependent variables were introduced in the Lince software to code all passing events. The independent variables were the scoring mode (1 - line goal, 2 - double goal, 3 - central goal) and the age group (1 - U13, 2 - U15), and passing actions were characterized for each team through the following dependent variables:
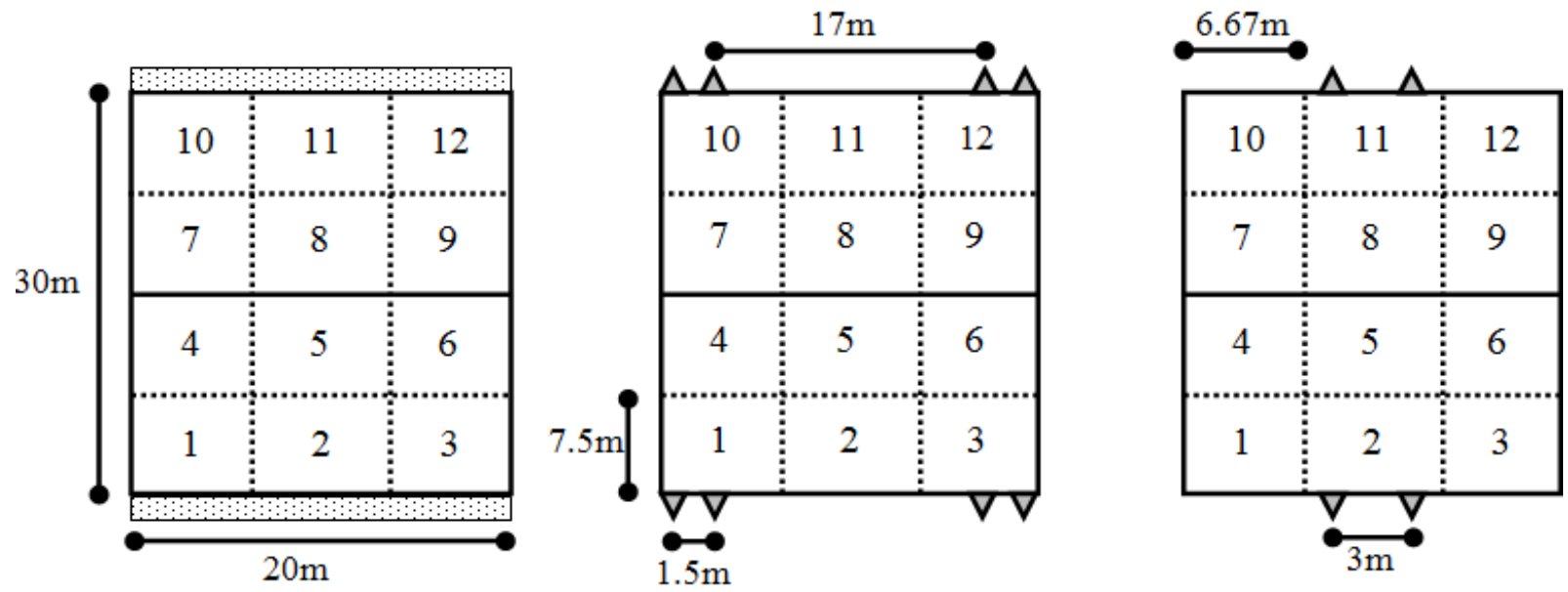

Figure 1. Experimental task schematic representation; from the left to the right, figures show line goal, double goal, and central goal conditions, respectively $[8,9]$ 
C.H. Almeida, A. Volossovitch, R. Duarte, Passing actions in small-sided and conditioned games

- Passing volume (continuous): mean number of successful passes performed in each scoring mode condition per age group.

- Passing zones (categorical): combined frequencies of pitch zones where the ball was passed by the ball carrier and effectively received by a teammate (i.e. in each passing action, the pass execution zone and the pass reception zone were both considered for statistical analysis). As represented in Figure 1, the pitch was divided into 12 equal sized zones, defining 4 sectors (defensive: zones 1, 2, and 3; defensive midfield: 4, 5, and 6; offensive midfield: 7, 8, and 9; offensive: 10, 11, and 12) and 3 corridors (left: 1, 4, 7, and 10; central: 2, 5, 8, and 11; right: $3,6,9$, and 12).

- Passing direction (categorical): number of passes performed with the use of $90^{\circ}$ sectors to represent 1 - forward, 2 - left, 3 - backwards, and 4 - right directions (Figure 2) [26]. In order to deal with diagonal passes $\left(45^{\circ}, 135^{\circ}, 225^{\circ}\right.$, or $\left.315^{\circ}\right)$, we adopted the designated 'sector criterion', in which diagonal passes within the same sector (e.g., defensive midfield) were considered left or right, and diagonal passes crossing 2 or more sectors were deemed forward or backwards.

Data collection was carried out by 2 trained researchers (more than 4 years of experience in performance analysis techniques) and data reliability was verified by retesting $16.7 \%$ of the sample (i.e. 6 randomly selected SSCGs). For intra-observer reliability procedures, the selected sample was re-tested 6 weeks after the first coding session to prevent any learning effect. The inter-observer reliability was assessed with the data from the first coding session performed by

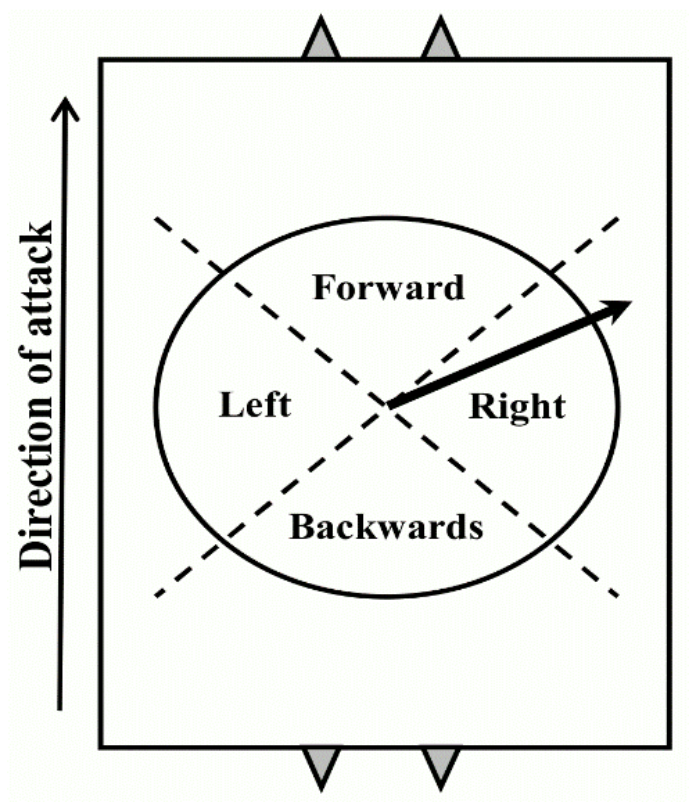

Figure 2. Definition of passing directions; adapted from O’Donoghue [26] both analysts. Weighted kappa was calculated to determine intra- and inter-observer agreement, and the values ranged from 0.91 (passing direction) to 0.97 (passing zone) for intra-observer reliability and from 0.87 (passing direction) to 0.92 (passing zone) for inter-observer reliability, which demonstrates a very good strength of agreement [27]. Ultimately, the coded data were exported into IBM SPSS Statistic 24.0 for analysis.

\section{Statistical analysis}

Effects of scoring mode (within-subjects) and age group (between-subjects) on passing volume were examined through mixed factorial ANOVA. The assumptions of normality, sphericity, and equality of error variances were previously verified $(p>0.05)$. Effect sizes were also calculated with the use of the obtained contrasts as proposed by Field [28]. Multinomial logistic regression analysis was applied to estimate the probability of passing zones and passing direction occurrences with the consideration of the scoring mode and age group. According to Field [28], these analyses break the dependent variables down into a series of comparisons between 2 categories, including the reference category. The final models, which better fit the data, involved only the main effects of predictor variables. Following a stepwise procedure, the interaction terms were tested in all models but none of them was significant; hence, no interactions were added to the models. The zone 2 (passing zones) and backwards (passing direction) were chosen as reference categories. The level of statistical significance was set at $p<0.05$.

\section{Ethical approval}

The research related to human use has been complied with all the relevant national regulations, institutional policies and in accordance the tenets of the Helsinki Declaration, and has been approved by the authors' institutional review board or equivalent committee.

\section{RESULTS}

Overall, a higher frequency of passes was observed for the line goal condition ( $n=1438 ; 35.5 \%)$, followed by double goal ( $n=1329 ; 32.8 \%$ ), and central goal $(n=$ $1285 ; 31.7 \%$ ). The U15 group ( $n=2144 ; 52.9 \%$ ) performed more passing actions than the U13 group $(n=$ 1908; 47.1\%). Table 1 shows the descriptive statistics of passing volume, passing zones, and passing direction in accordance with the scoring mode and age group. 
Table 1. Descriptive statistics of passing volume (mean \pm standard deviation), passing zones, and passing direction (absolute [and relative frequency: \%]), in accordance with the scoring mode and age group

\begin{tabular}{|c|c|c|c|c|c|}
\hline \multirow{2}{*}{$\begin{array}{l}\text { Variable/ } \\
\text { Category }\end{array}$} & \multicolumn{3}{|c|}{ Scoring mode } & \multicolumn{2}{|c|}{ Age group } \\
\hline & Line goal & Double goal & Central goal & U13 & U15 \\
\hline \multicolumn{6}{|l|}{ Continuous variable } \\
\hline Passing volume & $119.8 \pm 17.4$ & $110.8 \pm 15.8$ & $107.1 \pm 10.6$ & $106 \pm 12.9$ & $119.1 \pm 15.3$ \\
\hline \multicolumn{6}{|c|}{ Categorical variables } \\
\hline \multicolumn{6}{|c|}{ Passing zones } \\
\hline Zone 1 & $260(3.2)$ & $318(3.9)$ & $238(2.9)$ & $386(4.8)$ & $430(5.3)$ \\
\hline Zone 2 & $422(5.2)$ & $459(5.7)$ & $465(5.7)$ & $613(7.6)$ & $733(9.0)$ \\
\hline Zone 3 & $281(3.5)$ & $384(4.7)$ & $305(3.8)$ & $395(4.9)$ & $575(7.1)$ \\
\hline Zone 4 & 320 (3.9) & $257(3.2)$ & $241(3.0)$ & $388(4.8)$ & $430(5.3)$ \\
\hline Zone 5 & $406(5.0)$ & 316 (3.9) & $333(4.1)$ & $437(5.4)$ & $618(7.6)$ \\
\hline Zone 6 & $308(3.8)$ & $252(3.1)$ & $263(3.2)$ & 394 (4.9) & 429 (5.3) \\
\hline Zone 7 & $201(2.5)$ & 150 (1.9) & $165(2.0)$ & $250(3.1)$ & $266(3.3)$ \\
\hline Zone 8 & $204(2.5)$ & $161(2.0)$ & 157 (1.9) & $264(3.3)$ & $258(3.2)$ \\
\hline Zone 9 & $217(2.7)$ & 154 (1.9) & $163(2.0)$ & $294(3.6)$ & $240(3.0)$ \\
\hline Zone 10 & $93(1.1)$ & $70(0.9)$ & $89(1.1)$ & 157 (1.9) & $95(1.2)$ \\
\hline Zone 11 & $52(0.6)$ & $42(0.5)$ & $38(0.5)$ & $61(0.8)$ & $71(0.9)$ \\
\hline Zone 12 & $112(1.4)$ & $95(1.2)$ & $113(1.4)$ & $177(2.2)$ & $143(1.8)$ \\
\hline \multicolumn{6}{|l|}{ Passing direction } \\
\hline Backwards & $318(7.8)$ & $257(6.3)$ & 257 (6.3) & 451 (11.1) & $381(9.4)$ \\
\hline Right & $373(9.2)$ & 360 (8.9) & $330(8.1)$ & $464(11.5)$ & $599(14.8)$ \\
\hline Left & $355(8.8)$ & 367 (9.1) & $301(7.4)$ & 419 (10.3) & 604 (14.9) \\
\hline Forward & $392(8.7)$ & $345(8.5)$ & 397 (9.8) & $574(14.2)$ & $560(13.8)$ \\
\hline
\end{tabular}

Regardless of the scoring mode and age group, zone 2 was the most frequent zone explored to pass and receive the ball $(n=1346 ; 16.6 \%)$, while forward was the most used direction for passing the ball $(n=1134$; $30.0 \%$ ). Mixed ANOVA revealed a significant difference between line goal and central goal conditions for passing volume: $F(1,10)=8.054, p=0.018(r=0.67$; very large effect size); however, the comparison between double goal and central goal conditions was not significant: $F(1,10)=0.663, p=0.434(r=0.25$; small effect size). The interaction scoring mode $\times$ age group did not reach statistical significance: $F(2,20)=0.227$, $p=0.799$. The passing volume was significantly different between age groups: $F(1,10)=7.905, p=0.018$, representing a very large effect size: $r=0.66$ [28].

Table 2 displays the regression coefficients, Wald statistics, odds ratios, and 95\% confidence intervals for odds ratios (i.e. parameter estimates) for each fac- tor included in the models estimated through multinomial logistic regression. Given the large number of associations, only results reaching statistical significance $(p<0.05)$ are presented.

The Pearson and deviance values $(p>0.69)$ indicated that the predicted values were not significantly different from the observed values (i.e. the models had a good fit). The pseudo $R^{2}$ values (Cox \& Snell and Nagelkerke) revealed that the models presented smallsized effects. The scoring mode predicted whether youth teams performed significantly more passing actions in zones 1, 3, 4, 5, 6, 7, 8, and 9, compared with zone 2 . The probability of performing passing actions in zones 1 and 3 increased by $35.4 \%$ and $27.5 \%$, respectively, when playing with the double goal condition relatively to the central goal scoring mode. The comparison between line goal and central goal conditions showed that the odds of performing successful passing actions in 


\section{HUMAN MOVEMENT}

C.H. Almeida, A. Volossovitch, R. Duarte, Passing actions in small-sided and conditioned games

Table 2. Parameter estimates of multinomial logistic regression of passing zones and passing direction in accordance with the scoring mode and age group

$\begin{array}{llllll}\text { Variable/Category } & B & \text { Wald } & p & \text { OR } & 95 \% \mathrm{CI}\end{array}$

Passing zones (reference: zone 2)*

Zone 1

Scoring mode: double goal vs. central goal

0.303

7.865

0.005

1.354

$1.096-1.673$

Zone 3

Scoring mode: double goal vs. central goal

0.243

5.757

0.016

1.275

$1.045-1.554$

Age group: U13 vs. U15

$-0.195$

5.225

0.022

0.823

$0.696-0.973$

Zone 4

Scoring mode: line goal vs. central goal

0.380

12.233

0.000

1.462

$1.182-1.809$

Zone 5

Scoring mode: line goal vs. central goal

0.297

8.819

0.003

1.346

$1.106-1.637$

Age group: U13 vs. U15

$-0.171$

4.238

0.04

0.843

$0.716-0.992$

Zone 6

Scoring mode: line goal vs. central goal

0.254

5.580

0.018

1.289

$1.044-1.592$

Zone 7

Scoring mode: line goal vs. central goal

0.293

5.529

0.019

1.341

$1.050-1.712$

\section{Zone 8}

Scoring mode: line goal vs. central goal

0.357

8.067

0.005

1.429

$1.117-1.828$

\section{Zone 9}

Scoring mode: line goal vs. central goal

0.380

9.423

0.002

1.462

1.147-1.863

Age group: U13 vs. U15

0.377

13.457

0.000

1.458

$1.192-1.784$

Zone 10

Age group: U13 vs. U15

0.678

23.103

0.000

1.970

1.494-2.598

Zone 12

Age group: U13 vs. U15

0.390

9.724

0.002

1.477

$1.156-1.887$

Passing direction (reference: backwards)**

Right

Age group: U13 vs. U15

$-0.422$

20.569

0.000

0.655

$0.546-0.787$

Left

Age group: U13 vs. U15

$-0.532$

31.855

0.000

0.587

$0.488-0.706$

Forward

Scoring mode: line goal vs. central goal

$-0.224$

4.140

0.042

0.799

$0.694-1.088$

$B$ - regression coefficient, OR - odds ratio, CI - confidence interval

${ }^{*} R^{2}=0.02$ (Cox \& Snell), 0.02 (Nagelkerke), model $\chi^{2}(33)=160.825$

${ }^{*} R^{2}=0.014$ (Cox \& Snell), 0.015 (Nagelkerke), model $\chi^{2}(9)=57.016$

zones $4,5,6,7,8$, and 9 significantly increased in line goal by $46.2 \%, 34.6 \%, 28.9 \%, 34.1 \%, 42.9 \%$, and $46.2 \%$, respectively. In other words, the passing flow was considerably more pronounced in defensive midfield and offensive midfield sectors when youth teams were playing with the line goal constraint. We also found significant associations between the age group and the zones explored by youth players to circulate the ball.
In relation to the reference category - zone 2 - significant differences between U13 and U15 groups were noted in zones 3 ( $p=0.022), 5(p=0.04), 9(p<0.001)$, $10(p<0.001)$, and $12(p=0.002)$. In short, U13 teams were more likely than U15 to execute passing actions in more advanced pitch locations, namely in zones 9 (45.8\%), 10 (97\%), and 12 (47.7\%). On the contrary, as compared with U15, U13 teams were $17.7 \%$ and $15.7 \%$ 


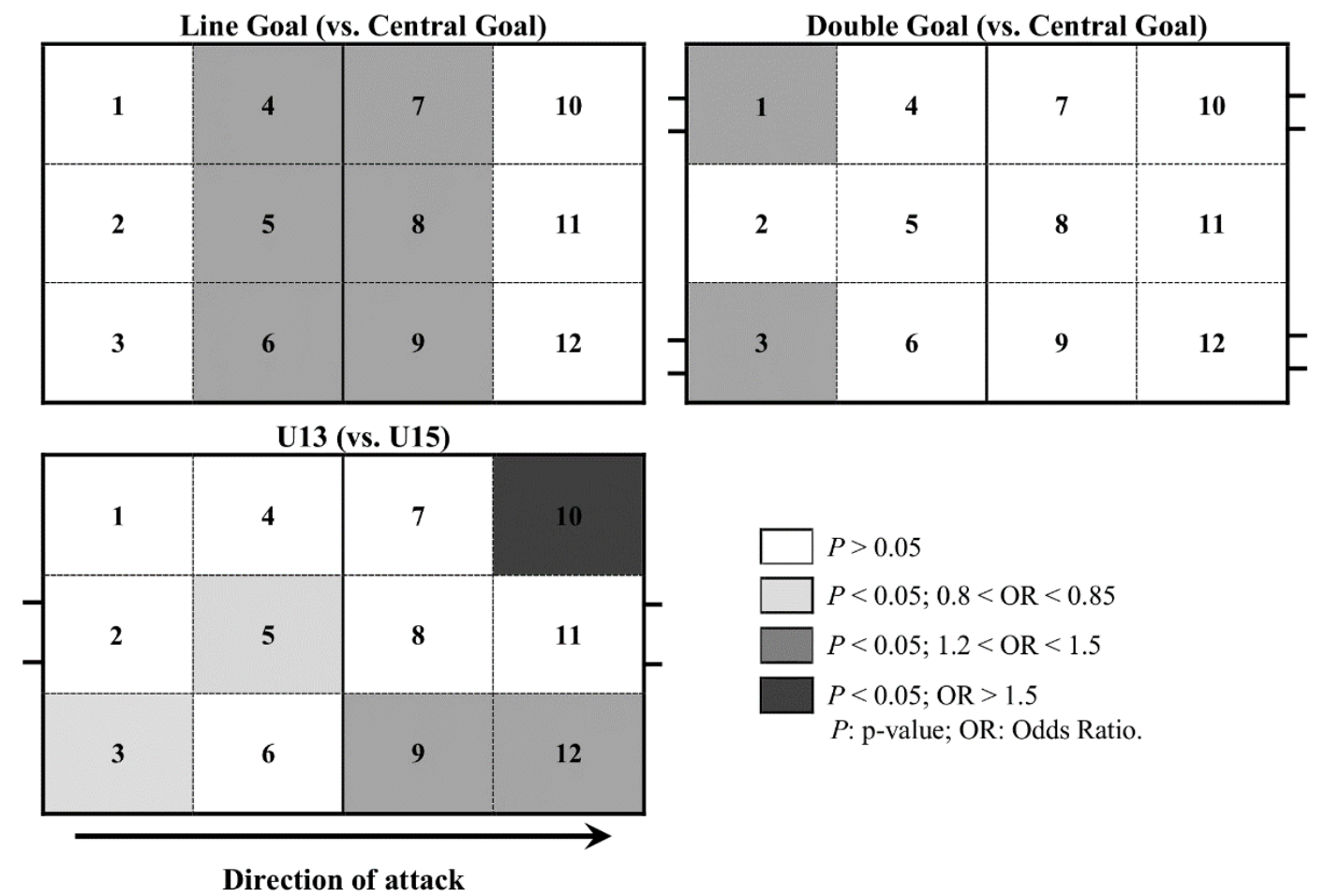

Figure 3. Predominant passing zones with the consideration of the scoring mode and age group (reference category: zone 2)

less likely to perform passing actions in zones 3 and 5 , respectively. Figure 3 provides a comprehensive insight into the effects of scoring mode and age group on the zones explored by players to pass the ball.

Both scoring mode and age group were found to be predictors of passing direction. A significant effect was identified when comparing line goal and central goal conditions $(p=0.042)$. In SSCGs with the line goal condition, the odds of teams to perform forward passes decreased by $20.1 \%$ compared with regular $4 \mathrm{v} 4$ games played with central goals. Additionally, the probabilities of performing passes to the left and to the right sides were significantly bigger in U15 teams $(41.3 \%$ and $34.5 \%$, respectively) compared with U13 ones $(p<0.001)$.

\section{DISCUSSION}

This study examined the effects of manipulating the scoring mode on the emergence of passing actions performed by U13 and U15 youth teams in 4v4 SSCGs. For this purpose, 3 game-related variables (passing volume, passing zones, and passing direction) were notated and compared in different practice contexts.

Researchers have advocated that SSCGs, which are characterized by random and variable structure, promote the development of decision-making and game intelligence, as well as better long-term learning and transfer of skill to competitive game-play contexts [2,
4-6]. The results confirmed our first hypothesis: manipulating the scoring mode in SSCGs influenced the opportunities for passing actions among young players. A significant scoring mode effect was found on passing volume (with a very large effect size). In particular, the line goal constraint provided teams with a favourable performance environment stimulating a higher number of passes. First, line goal constrains players to control the ball in the opposing end zone, instead of just shooting at goal as occurs in double and central goal conditions [8]. Since players need to move the ball forward under control instead of long and mid-range shooting, a high stimulus is placed on passing actions in more advanced pitch areas. Secondly, increasing the scoring area or the number of goals tends to decrease the defensive organization and increase the available space to perform successful passes $[10,13,14]$ as compared with the central goal constraint. Hence, SSCGs with line goal seem to be a fruitful task to foster possession-based strategies in searching for the best scoring chance. Recently, Brandes et al. [11] and Pulling et al. [12] found contrary results in U13 and U16 players, since a greater number of on-the-ball actions (including passes) was performed in games played with goal-posts positioned centrally. Further research on SSCGs is needed to clarify these contradictions in youth soccer practice.

To successfully perform a pass, the ball carrier needs to perceive the location of a teammate who can receive 
C.H. Almeida, A. Volossovitch, R. Duarte, Passing actions in small-sided and conditioned games

the ball during a certain space-time window, and pass it with accurate direction to satisfy the emergent opportunities offered by the game environment [29]. The manipulation of scoring mode also influenced the pitch locations used by youth teams to explore their opportunities for passing actions. For instance, whilst the double goal condition prompted a larger use of lateral corridors in the defensive sector (zones 1 and 3), the passing flow dynamics were considerably more pronounced in defensive midfield and offensive midfield sectors when playing with the line goal constraint. Indeed, the opponents' defensive pressure is commonly more intensive in central zones, reducing the possibilities for successful passes during offensive sequences [10]. A wider area to score or small goals placed widely at the goal line tend to decrease the natural tendency of youth players to seek for the central corridor to perform passing actions as in standard game situations (central goal) [8, 14]. In addition, the line goal condition encouraged off-the-ball players to progress into advanced positions on the pitch in order to potentially receive the ball near the opposing end zone [12]. However, the odds of passing sideways (i.e. left and right directions) increased in the line goal mode in relation to $4 \mathrm{v} 4$ games played with central goals, in which forward was the most frequent passing direction. According to Rein et al. [20], passes crossing longitudinal pitch zones (forward) are usually more effective than passes performed within pitch zones and sectors (side-to-side directions) owing to the increased likelihood of outplaying more defenders. These assertions imply that the emergence of different passing actions and attacking strategies of youth teams can be modulated by coaches in SSCGs by manipulating specific task constraints such as the scoring mode [6, 11, 25, 29].

Irrespective of the scoring mode, the second hypothesis was also proved: our results confirmed the significant age-related effects on players' passing behaviours. As expected, the passing volume was greater in the U15 group. Previous research has demonstrated that older and more experienced players have more proficient technical performances in soccer competitive settings [8, 19, 22]. For example, higher passing rates were observed in experienced U15 players compared with non-experienced players in 2 SSCG formats [19], and U17 teams presented higher passing densities than U15 teams [22]. This is particularly relevant once available literature has shown a clear association between match outcomes and high passing work rates [22, 30].

The pitch zones used to circulate the ball and the passing direction were affected by the age and the level of expertise of participants. While the odds of perform- ing passing actions in more advanced pitch positions were higher in U13 teams, the older players executed more sideway passes. The tendency of younger or less skilled teams to adopt more elongated playing shapes during game-play might explain these findings $[8$, 15-18]. A deeper and narrow spatial distribution of players on the field might limit the available space to move the ball across it (sideways), probably encouraging players to solve game situations with the prevalence of individual actions. This game environment is deemed to promote affordances for fast approaches to opponents' scoring targets through a direct playing style, predominantly based on longitudinal passes (goal-to-goal direction) [15, 16, 19]. In turn, older and more experienced players tend to present a wider pitch occupation, creating proper affordances for possessionbased strategies, where passing sideways is a prevalent option to patiently move the ball, create overloads supporting the ball carrier, and find the best opportunity to score a goal $[8,15-17]$.

From a practical point of view, coaches should use the present findings to guide exploratory learning under the inherent variability of game-play situations [5, 6]. The line goal constraint provides a good stimulus to enhance possession-based strategies looking to exploit the appropriate timing to move forward on the pitch and stop the ball in the opposing end zone. The SSCGs with double goal require a great variability of passing actions in order to move from defensive pressure zones to less congested areas of the pitch, changing rapidly the angle of attack [12]. Central goal conditions are useful to retain the specific tendencies of competitive match-play, leading to a smaller number of passes and a more direct approach to the opponents' target by passing the ball forward. These results are in line with previous research, which has clearly demonstrated that age and level of expertise influence players' technical and tactical behaviours [8, 15-18, 22].

The findings provided by this study are limited because the notational variables gave only a partial picture of the teams' behaviour. In future studies, the notational analysis should be complemented with other measures, such as network analysis or compound positional variables, to reveal how players coordinate their efforts in space and time to reach a common goal $[22,31]$. Since participants were selected from a single club team and the number of individuals from each age group was small, caution is recommended when generalizing the reported findings. 


\section{CONCLUSIONS}

The presented study showed how the opportunities for passing actions could be constrained by changing the dimensions, position, shape, and/or number of scoring targets in SSCGs. We encourage coaches to use these task constraints for helping youngsters to attune to action-relevant information and explore different playing strategies to achieve specific performance outcomes. Our results also confirmed that the age group and the level of expertise should be considered for designing representative practice tasks in youth soccer. The older and more experienced players revealed a greater ability not only to perform more passing actions, but also to explore wider zones for moving the ball, which entails a superior tactical understanding of the game. Further research is needed to verify the findings of this work for other age groups and playing levels (e.g., sub-elite and elite players), taking into account the potential of combining discrete passing events with positional data and/or network analysis in order to better understand the factors that influence team coordination and skill acquisition in youth soccer.

\section{Acknowledgments}

The authors would like to thank Rafael Inácio, Tiago Salvador, and Paulo Conceição for their valuable support in the experimental sessions and data collection.

\section{Disclosure statement}

No author has any financial interest or received any financial benefit from this research.

\section{Conflict of interest}

Authors state no conflict of interest.

\section{References}

1. Ford PR, Yates I, Williams AM. An analysis of practice activities and instructional behaviours used by youth soccer coaches during practice: exploring the link between science and application. J Sports Sci. 2010;28(5): 483-495; doi: 10.1080/02640410903582750.

2. O’Connor D, Larkin P, Williams AM. Observations of youth football training: how do coaches structure training sessions for player development? J Sports Sci. 2018;36(1):39-47;doi:10.1080/02640414.2016.1277034.

3. Vaeyens R, Lenoir M, Williams AM, Philippaerts RM. Talent identification and development programmes in sport: current models and future directions. Sports Med. 2008;38(9):703-714; doi: 10.2165/00007256-20083809000001.
4. Oppici L, Panchuk D, Serpiello FR, Farrow D. Long-term practice with domain-specific task constraints influences perceptual skills. Front Psychol. 2017;8:1387; doi: 10.3389/fpsyg.2017.01387.

5. Button C, Lee C-YM, Mazumder AD, Tan WKC, Chow J-Y. Empirical investigations of nonlinear motor learning. Open Sports Sci J. 2012;5(Suppl 1-M6):49-58; doi: 10.2174/1875399X01205010049.

6. Davids K, Araújo D, Correia V, Vilar L. How small-sided and conditioned games enhance acquisition of movement and decision-making skills. Exerc Sport Sci Rev. 2013;41(3):154-161; doi: 10.1097/JES.0b013e318292f3ec.

7. Almeida CH, Ferreira AP, Volossovitch A. Manipulating task constraints in small-sided soccer games: performance analysis and practical implications. Open Sports SciJ.2012;5:174-180;doi:10.2174/1875399X01205010174.

8. Almeida CH, Duarte R, Volossovitch A, Ferreira AP. Scoring mode and age-related effects on youth soccer teams' defensive performance during small-sided games. J Sports Sci. 2016;34(14):1355-1362; doi: 10.1080/ 02640414.2016.1150602.

9. Duarte R, Araújo D, Fernandes O, Travassos B, Folgado H, Diniz A, et al. Effects of different practice task constraints on fluctuations of player heart rate in smallsided football games. Open Sports Sci J. 2010;3(1):13-15; doi: 10.2174/1875399X01003010013.

10. Clemente FM, Wong DP, Martins FML, Mendes RS. Acute effects of the number of players and scoring method on physiological, physical, and technical performance in small-sided soccer games. Res Sports Med. 2014;22(4): 380-397; doi: 10.1080/15438627.2014.951761.

11. Brandes M, Müller L, Heitmann A. Physiological responses, time-motion characteristics and game performance in 4 vs. 4 small-sided games in elite youth soccer players: different number of mini-goals vs. stop-ball. Sci Med Football. 2017;1(2):126-131; doi: 10.1080/24733938. 2017.1283432.

12. Pulling C, Twitchen A, Pettefer C. Goal format in smallsided soccer games: technical actions and offensive scenarios of prepubescent players. Sports. 2016;4(4):53; doi: 10.3390/sports4040053.

13. Travassos B, Gonçalves B, Marcelino R, Monteiro R, Sampaio J. How perceiving additional targets modifies teams' tactical behavior during football small-sided games. Hum Mov Sci. 2014;38:241-250; doi: 10.1016/j. humov.2014.10.005.

14. Castellano J, Silva P, Usabiaga O, Barreira D. The influence of scoring targets and outer-floaters on attacking and defending team dispersion, shape and creation of space during small-sided soccer games. J Hum Kinet. 2016;51:153-163; doi: 10.1515/hukin-2015-0178.

15. Barnabé L, Volossovitch A, Duarte R, Ferreira AP, Davids K. Age-related effects of practice experience on collective behaviours of football players in small-sided games. Hum Mov Sci. 2016;48:74-81; doi: 10.1016/j. humov.2016.04.007. 


\section{HUMAN MOVEMENT}

C.H. Almeida, A. Volossovitch, R. Duarte, Passing actions in small-sided and conditioned games

16. Folgado H, Lemmink KA, Frencken W, Sampaio J. Length, width and centroid distance as measures of teams tactical performance in youth football. Eur J Sport Sci. 2014;14(Suppl 1):S487-S492; doi: 10.1080/17461391. 2012.730060.

17. Olthof SB, Frencken WG, Lemmink KA. The older, the wider: on-field tactical behavior of elite-standard youth soccer players in small-sided games. Hum Mov Sci. 2015;41:92-102; doi: 10.1016/j.humov.2015.02.004.

18. Silva P, Travassos B, Vilar L, Aguiar P, Davids K, Araújo D, et al. Numerical relations and skill level constrain co-adaptive behaviors of agents in sports teams. PLoS One. 2014;9(9):e107112; doi: 10.1371/journal. pone.0107112.

19. Almeida CH, Ferreira AP, Volossovitch A. Offensive sequences in youth soccer: effects of experience and small-sided games. J Hum Kinet. 2013;36:97-106; doi: 10.2478/hukin-2013-0010.

20. Rein R, Raabe D, Memmert D. "Which pass is better?" Novel approaches to assess passing effectiveness in elite soccer. Hum Mov Sci. 2017;55:172-181; doi: 10.1016/j. humov.2017.07.010.

21. Amatria M, Lapresa D, Arana J, Anguera MT, Jonsson GK. Detection and selection of behavioral patterns using Theme: a concrete example in grassroots soccer. Sports. 2017;5(1):20; doi: 10.3390/sports5010020.

22. Gonçalves B, Coutinho D, Santos S, Lago-Peñas C, Jiménez S, Sampaio J. Exploring team passing networks and player movement dynamics in youth association football. PLoS One. 2017;12(1):e0171156; doi: 10.1371/ journal.pone.0171156.

23. Brito Â, Roriz P, Silva P, Duarte R, Garganta J. Effects of pitch surface and playing position on external load activity profiles and technical demands of young soccer players in match play. Int J Perform Anal Sport. 2017;1-17; doi: 10.1080/24748668.2017.1407207.

24. Gabin B, Camerino O, Anguera MT, Castañer M. Lince: multiplatform sport analysis software. Procedia Soc Behav Sci. 2012;46:4692-4694; doi: 10.1016/j.sbspro. 2012.06.320.

25. Corrêa UC, Vilar L, Davids K, Renshaw I. Informational constraints on the emergence of passing direction in the team sport of futsal. Eur J Sport Sci. 2014;14(2): 169-176; doi: 10.1080/17461391.2012.730063.

26. O’Donoghue P. An introduction to performance analysis in sport. Abingdon, Oxon: Routledge; 2015.

27. O’Donoghue P. Research methods for sports performance analysis. London: Routledge; 2010.

28. Field A. Discovering statistics using SPSS, $3^{\text {rd }}$ ed. London: SAGE Publications Ltd; 2009.

29. Travassos B, Duarte R, Vilar L, Davids K, Araújo D. Practice task design in team sports: representativeness enhanced by increasing opportunities for action. J Sports Sci. 2012;30(13):1447-1454; doi: 10.1080/02640414. 2012.712716 .

30. Grund TU. Network structure and team performance: the case of English Premier League soccer teams. Soc
Networks. 2012;34(4):682-690; doi: 10.1016/j.socnet. 2012.08.004.

31. Duarte R, Araújo D, Correia V, Davids K. Sports teams as superorganisms: implications of sociobiological models of behaviour for research and practice in team sports performance analysis. Sports Med. 2012;42(8):633642; doi: 10.2165/11632450-000000000-00000. 